\title{
DNA Damage, Mutagenesis, and DNA Repair
}

\author{
Ashis Basu, ${ }^{1}$ Suse Broyde, ${ }^{2}$ Shigenori Iwai, ${ }^{3}$ and Caroline Kisker ${ }^{4}$ \\ ${ }^{1}$ Department of Chemistry, University of Connecticut, Storrs, CT 06269, USA \\ ${ }^{2}$ Department of Biology, New York University, New York, NY 10003, USA \\ ${ }^{3}$ Graduate School of Engineering Science, Osaka University, 1-3 Machikaneyama, Toyonaka, Osaka 560-8531, Japan \\ ${ }^{4}$ Rudolf Virchow Center for Experimental Biomedicine, Institute for Structural Biology, University of Würzburg, \\ 97080 Würzburg, Germany
}

Correspondence should be addressed to Ashis Basu, ashis.basu@uconn.edu

Received 8 October 2010; Accepted 12 October 2010

Copyright (C) 2010 Ashis Basu et al. This is an open access article distributed under the Creative Commons Attribution License, which permits unrestricted use, distribution, and reproduction in any medium, provided the original work is properly cited.

This special issue of the Journal of Nucleic Acids is dedicated to DNA damage and two important biological consequences provoked by such damage: lesion repair and lesion-induced mutagenesis. These phenomena have attracted broad interest among a large community of scientists that cross disciplines from mathematics, physics, chemistry, and biology to clinical scientists. The importance of DNA damage to human disease, especially cancer, is the common denominator for the widespread fascination with this area, as it spans from the molecular and mechanistic to the cellular, organismal, and therapeutic levels. Hence, papers are presented that showcase the unique strengths that emerge when researchers from a variety of intellectual perspectives focus on basic scientific challenges that must be addressed to improve human health.

The area of DNA damage, mutagenesis, and DNA repair is rapidly evolving. It is, therefore, gratifying to present in one rich volume the most current work from an array of leaders in the field, who offer up-to-date review articles as well as their most recent new research results. Included are DNA damages that may be endogenous, resulting from normal biochemical processes that have unwanted harmful outcomes, or exogenous, stemming from environmental causes such as tobacco smoke. Advanced mass spectrometry methods for damage detection and their processing, a current tour de force that plays a critical role in the field, are presented. Also featured are current molecular understandings of DNA repair mechanisms and mechanisms of damage-processing by DNA polymerases and accessory proteins. On the organismal level, all three kingdoms of life are represented, and among the eukaryotes the range spans from yeast to protozoa to vertebrates.

Accordingly, we proudly present this special issue of the Journal of Nucleic Acids. We thank the contributors for their outstanding work and the many reviewers who served conscientiously and tirelessly to assure an issue that meets the highest standards.

Ashis Basu

Suse Broyde

Shigenori Iwai

Caroline Kisker 

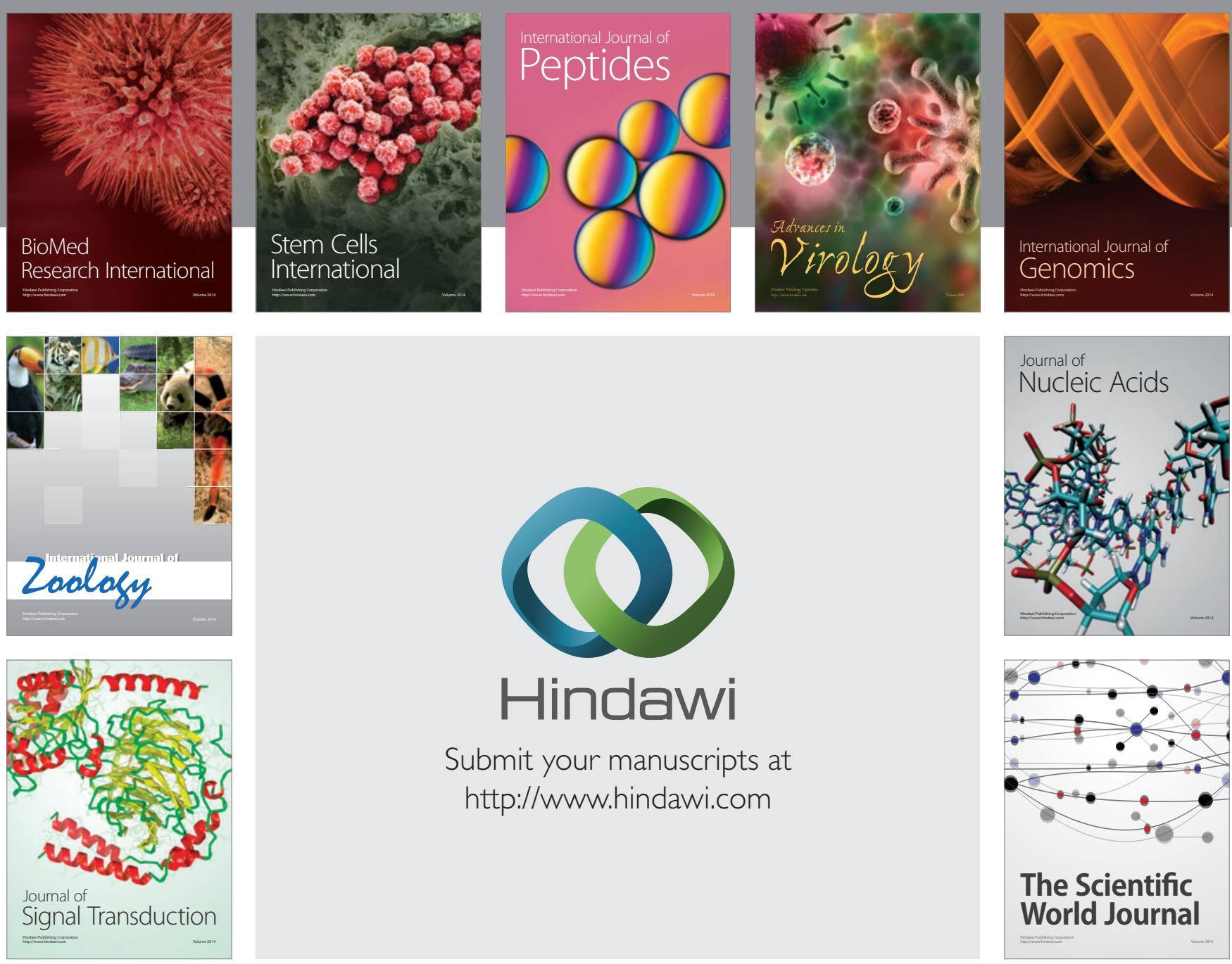

Submit your manuscripts at

http://www.hindawi.com
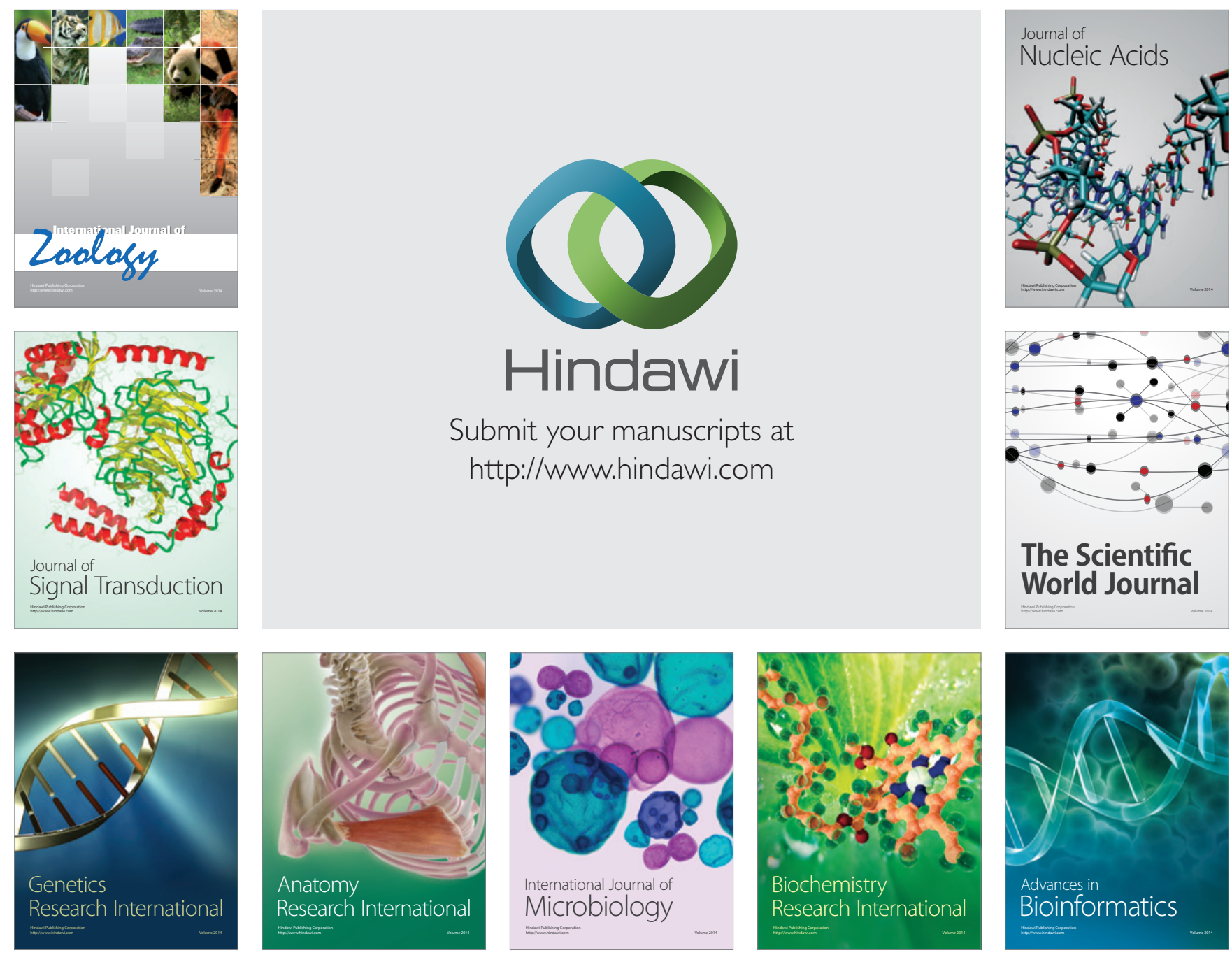

The Scientific World Journal
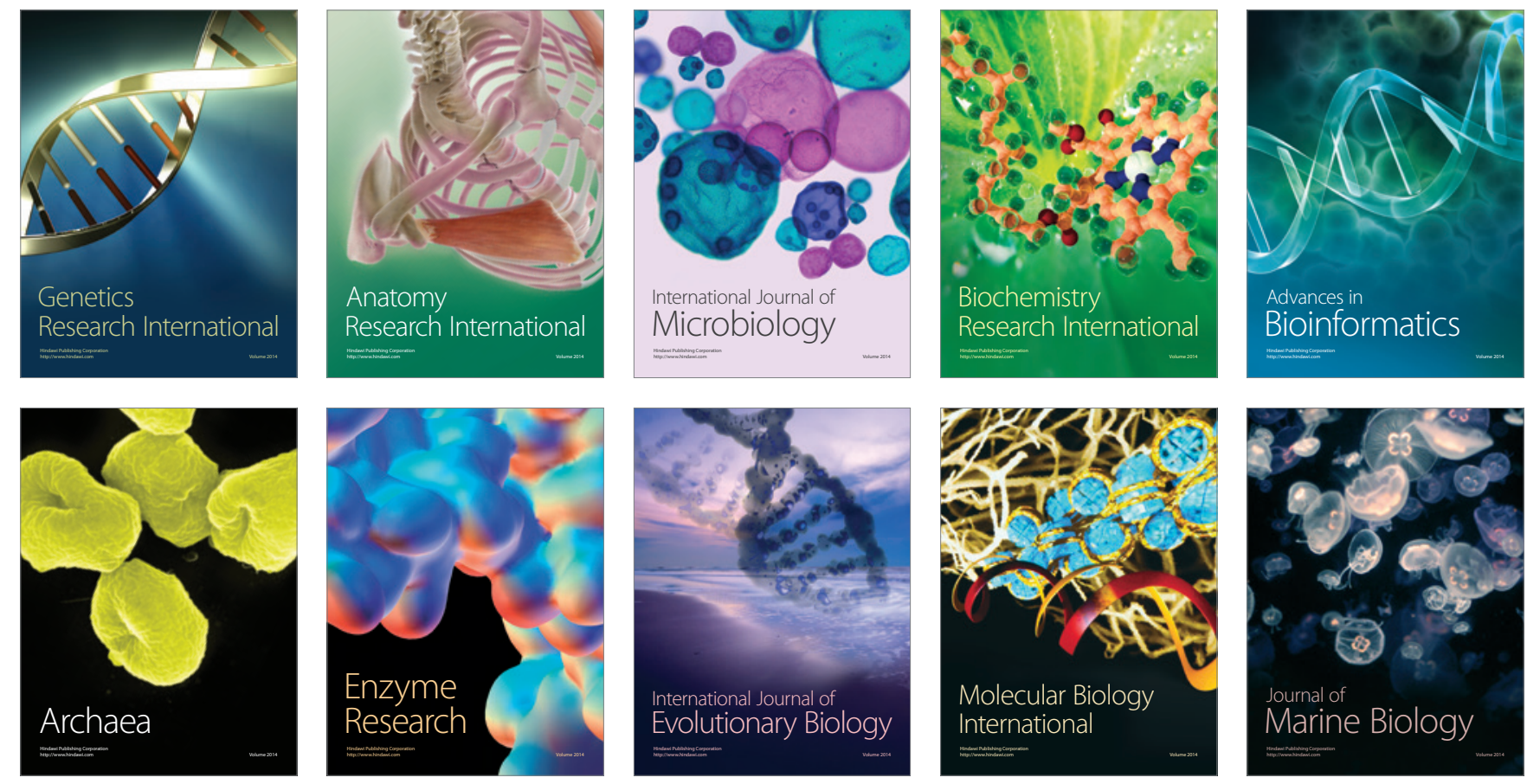